\title{
The trajectory of illness and the pattern of care seeking by leprosy patients in a leprosy endemic district of Bangladesh
}

\author{
Mohammad Monjurul Karim ${ }^{\mathrm{a}}$, Ari Probandari ${ }^{\mathrm{b}}$, Hasnat Alamgir ${ }^{\mathrm{c}}$, \\ Khorshed Alam ${ }^{\mathrm{d}} \&$ Adi Utarini ${ }^{\mathrm{e}}$ \\ anternational Master Program in Public Health, Faculty of Medicine, \\ Public Health and Nursing, Universitas Gadjah Mada, Yogyakarta, \\ Indonesia \\ ${ }^{\mathrm{b}}$ Department of Public Health, Universitas Sebelas Maret, Indonesia \\ ${ }^{\mathrm{c}}$ International University of Business Agriculture and Technology (IUBAT), \\ Bangladesh \\ ${ }^{\mathrm{d}}$ Project Manager, Rural Health Programme, The Leprosy Mission \\ International Bangladesh (TLMIB), Bangladesh \\ ${ }^{\mathrm{e}}$ Department of Health Policy and Management, Faculty of Medicine, Public \\ Health and Nursing, Universitas Gadjah Mada, Yogyakarta, Indonesia
}

Submitted 23 January 2021; Accepted 9 August 2021

\begin{abstract}
Summary
Background Persons affected by leprosy usually prefer to hide their condition and often come to the health facility after visible Grade 2 disabilities start to appear. They are unaware of the diagnosis or of the subsequent consequences and decline to seek care at the early stage of the disease progression. This study aims to describe the trajectory of this illness and the patterns of care seeking by leprosy patients in Bangladesh.

Methods This qualitative study relied on in-depth interviews in Nilphamri district which is known to be a leprosy endemic district in Bangladesh. Persons affected by leprosy over 18 years of age with a Grade 2 disability were selected for interview. A total of thirteen respondents were interviewed. Thematic analysis was used to interpret the data to identify themes, explore emerging patterns, and examine commonalities and contradictions.

Results Lack of awareness in the general population about leprosy and a poor referral system appeared to be the major barriers to seeking health care at an early stage of disease progression. Persons affected by leprosy remain hidden for a long time because of its slow progression, leading to the development of more devastating disabling conditions.

Conclusion Programmes to create awareness about leprosy may help in motivating people to access appropriate health care in a timely manner, and comply with the treatment requirements and recommendations. Location and functions of leprosy
\end{abstract}

Correspondence to: Mohammad Monjurul Karim (e-mail: karim@mail.ugm.ac.id) 
clinics should be made known to the surrounding communities. Leprosy affected persons will be more eager to use the service if they know about the facility. Important determinants like the costs and economic burden should be investigated in depth in future studies to help formulate leprosy care policies and strategies.

Keywords: Leprosy, delay in diagnosis

\section{Introduction}

Leprosy is a chronic slow-acting infectious disease caused by a bacillus, Mycobacterium leprae. It primarily affects the peripheral nerves, mucosa of the upper respiratory tract, skin and eyes. The early stage of the disease develops with pale-coloured skin patches with loss of sensation and enlarged peripheral nerve with impaired function. Untreated and delayed cases develop chronic ulcers, leprosy reactions and neuritis that can lead to permanent disability in hands, legs and eyes. ${ }^{1,2}$

WHO declared the elimination of leprosy as a public health problem globally in the year 2000. After a rapid decline in new case detection following the inception of multidrug therapy in the 1981, the post-2000 era showed a steady new case detection rate between 200,000 300,000 cases per year globally. The 2005-2014 trend showed a slight decrease in new case detection over the first five years. However, case detection remained steady at over 200,000 yearly in the last five years. The Grade 2 disability (G2D) case detection also remained stable between 13,000 to 14,000 cases per year in these 10 years; this was quite alarming. ${ }^{3}$ Leprosy is listed as one of the neglected tropical diseases which affect the poorest populations of the world living in hard to reach or conflict zones. Weak political will and low public health priorities labelled the disease as neglected. ${ }^{4}$ The situation in Bangladesh is similar.

A earlier study estimated the prevalence of previously undiagnosed leprosy (PPUL) to be 15.1 cases per 10,000 which is six times higher than the registered prevalence in Bangladesh. ${ }^{5}$ As registered prevalence depends on passive case detection, many people remain untraced. The case detection rate and G2D remained stable between 2008 and 2017. ${ }^{6}$ This is an indication of the concept of "hidden cases" remaining in the community who are reluctant to seek care at the early stage of their disease. Early stage refers to the initial stage of skin patches, discoloration, and loss of skin sensation. Generally, it does not include any visible deformity or damage. These symptoms may later develop into G2D. ${ }^{7}$ The early cases remain hidden and suffer from a much greater degree of disability over time. Many infected leprosy patients are often not diagnosed officially and may only be found if there is an active survey taking place. ${ }^{8}$ After the elimination era, reduced funding impacted the efforts of active case detection in Bangladesh. ${ }^{9}$ The effort to find the causes of delayed case detection and hidden cases is not evident in the literature.

The report "Operational Plan Tuberculosis and Leprosy Control, Bangladesh" released in 2011 indicated five districts, namely, Nilphamari, Panchagarh, Gaibandha, Khagrachari and Bandarban ${ }^{10}$ as having prevalence rate higher than 1 per 10,000 population. Among the five districts, the first three are located the northwest of Bangladesh. Nilphamari has a literacy rate around $50 \%{ }^{11}$ whereas the national literacy level is over $73 \% .{ }^{12}$ The majority of people work as farmers and day labourers. The poverty headcount ratio is $34.7 \%$, slightly higher than national ratio of $31.5 \%$. $^{13}$ 


\section{STUDY SETTING}

Nilphmari is located at the northern part of the country, about $400 \mathrm{~km}$ from the capital city of Dhaka. The district detected 275 new cases including 123 males and 152 females and the detection rate was 1.02 per 10,000 population, the highest in the country in $2017 .{ }^{14}$ Among the new cases, sixteen (5.9\%) were registered with G2D suggesting they are delayed in seeking treatment. ${ }^{15}$ The Leprosy Mission International Bangladesh serves through six Upazila Health Complexes (UHC - local health centres) for case detection and Multi-Drug Therapy (MDT), and leprosy complication management in the district. The Danish Bangladesh Leprosy Mission (DBLM) Hospital is also located in this district.

This study was expected to reveal some aspects of delayed service seeking behaviour by exploring the trajectory of illness development and the patterns of care seeking by leprosy patients in Nilphamari. This study was designed to understand the causes of delayed case detection from the patients' perspective. This implementation research explored barriers to effective and quality execution of health interventions, strategies and policies as well as a method of promoting the systematic application of research findings in practice.

\section{Methods}

\section{STUDY SETTING}

The study was conducted in Nilphamari district of Bangladesh, a highly endemic district.

\section{RESEARCH DESIGN}

A qualitative phenomenology approach was used in this study to reveal the commonality and experience of a particular group of people through in-depth interviews (IDI).

\section{RESEARCH INFORMANTS AND SAMPLING}

In this study, the population was defined as leprosy-affected people over 18 years of age with G2D. G2D was defined as visible deformity or damage in hands or feet, or severe visual impairment (vison: worse than 6/60) or both of these together. ${ }^{7}$ The inclusion criteria were: (1) diagnosed leprosy-affected people with G2D over 18 years of age, and (2) people who completed MDT in the year 2018 and 2019. Criterion sampling method was used for reaching information-rich cases. It helped to get important qualitative information.

The patient register book was used to find information-rich cases among the list of the patients. This was done by taking active help of the leprosy clinic officers who were familiar to the patients and knowledgeable about their disease condition. To protect the privacy of patients, the clinical officers contacted the potential participants. Once agreed, the principal investigator (MMK) approached the patients for the interview. Out of the total nineteen participants approached, five were unable to participate for personal reasons. One participant was excluded from the interview list due to a language barrier. Prior to the interviews, the investigator explained the purpose of the research. All the respondents were given a unique code for all data collection tools. All thirteen subjects were interviewed in a quiet place to protect privacy and avoid external distraction as the health care centres are very busy and noisy.

\section{DATA COLLECTION AND ANALYSIS}

Data collection was done by the principal investigator (MMK) who was an MPH student at that time along with a research assistant (HR). Both of them followed and maintained data 


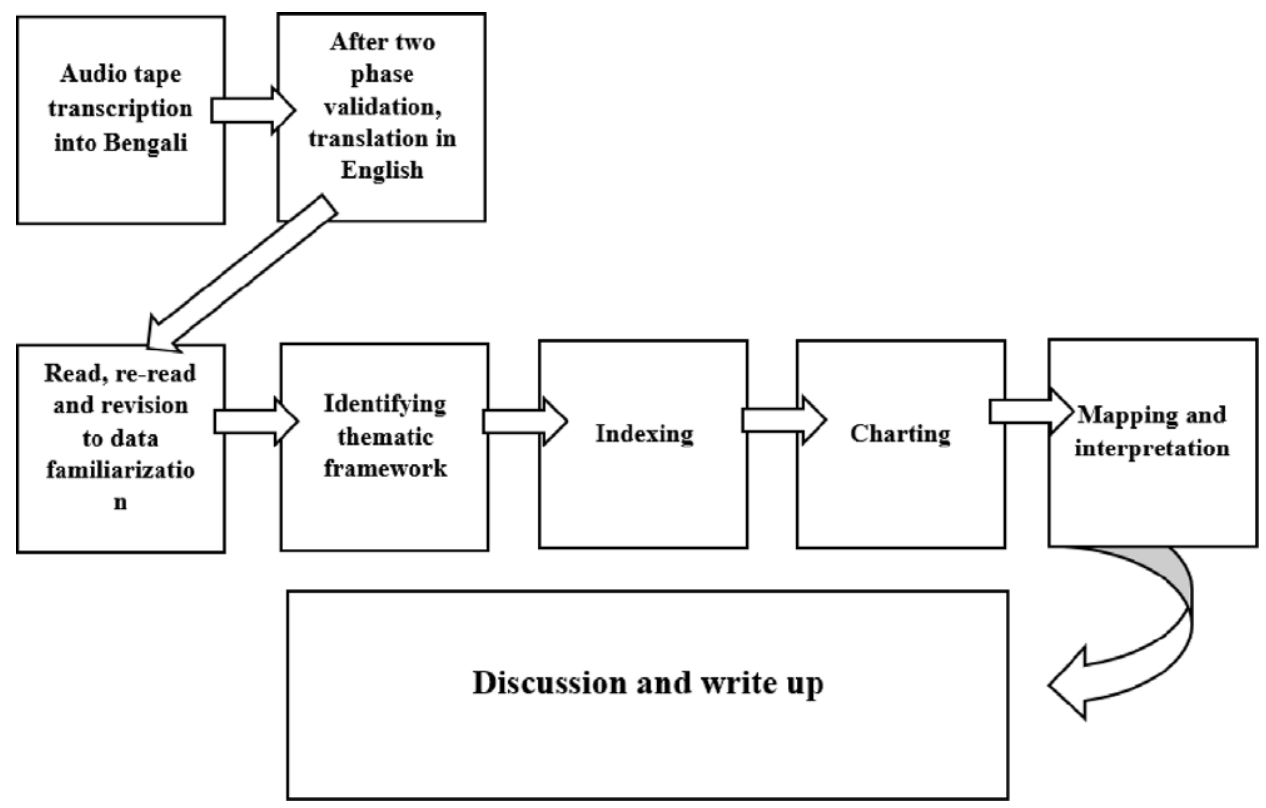

Figure 1. Data analysis steps.

privacy. The process of analysis is illustrated in Figure 1. A total of thirteen participants were interviewed at the Leprosy Centre of Upazila Health Complex. At this stage, the principal investigator started to receive data repetition from the participants and no new information was coming; thus, recruiting was stopped. The duration of the interviews was between 45 and $50 \mathrm{~min}$. Two audio recorders were used to avoid any technical failure to record the interviews. After ensuring the audio record was audible, the data were transcribed to a written format. This process was completed by both principal investigator and research assistant. In the case of noisy interfaces and unclear discussion, field notes were used in the transcription process. After transcription, a two-phase validation of the transcribed data was done. A different transcriber checked the transcription with the audio data. This was repeated by the principal investigator. After validating the transcriptions of the data, the text was translated into English. This was conducted by a different translator.

Translated data was then reviewed by the principal investigator. Thematic analysis was used to analyse the data. A data matrix was produced through data familiarization and then charting of data into a table. Extensive read, re-read and revisions were done to conduct the thematic analysis to explore emerging patterns, identify themes, examine commonalities and contradictions in the data and allow a comparison by case and category of participants.

\section{Research ethics}

Ethical approval was obtained from the Medical and Health Research Ethics Committee (MHREC), Faculty of Medicine, Public Health and Nursing, Universitas of Gadjah Mada (Ref no.: KE/FK/0589/EC/2019) and the ethical review board of Asian Institute of Disability and Development (AIDD) Human Research Ethics Committee (HREC) (Ref no.: southasia-hrec2019-7-01). A signed informed consent was taken from each respondent. All the information 
provided by the respondents in the study was kept confidential and all respondents were identified with a pre-defined code instead of their name. Participation in this study was voluntary.

\section{Results}

Nine of the thirteen participants were male. All of respondents were married but one was a widow. Literacy level was relatively low among the participants, seven had no literacy, while the others had some educational qualifications. In general, they represented the lower socioeconomic population group.

The study identified two thematic areas, namely the experience of illness of people affected by leprosy and the pattern of seeking leprosy services available in the community.

Symptoms of leprosy played an important role in accessing leprosy care services. Symptoms of the disease showed a pattern but the initial symptoms were often different in different people. Some of the respondents noticed their skin pathces whereas others suffer from physical deformities of hands or feet. One of them stated:

“... It started with a skin mark on the hand. My husband noticed it and asked why the skin marks are getting worse every day..." (IDI 001, 32 year old female)

This is an example of initial symptoms where skin marks were worsening over time. This was a common symptom pattern reported by around one third of the people. On the contrary, one respondent mentioned:

“... The small finger of my left-hand became bent and gradually it started on my right hand too.

..." (IDI 014, 46 year old male)

Seven out of thirteen reported some form of skin marks either in hand or leg or sometimes together as their first symptom; these were later spread throughout the body over time. The skin patches became numb over time which was often referred to as thickening of the skin. At a later stage, they lost the sense partially or fully on those spots. Unfortunately, skin patches were generally not seen as serious enough to seek care.

Once they noticed the patches, they took medication from a local doctor or pharmacy and waited to see the outcome. Four respondents recognised the decreasing strength of the hand and legs as their first symptom, instead of skin patches. Their skin patches were usually identified during assessment at the leprosy clinic. Loss of strength was also not taken seriously, as it was considered as general weakness. The remaining rspondents reported wounds either on hand or foot during work, that later turned into a sore which did not recover with general treatment.

In the next stage, soreness occurred either in fingers, toes or sometimes at the heel. The attempt to seek care started once the sore was not responding to general medication taken from the local pharmacy. Unhealed sores on body parts created tension and they were desperate to seek care at the appropriate place. Over half of the respondents reported visits to homoeopathic, kabiraj, jharfuk or faith-based healers. The visits were either at one place at a time or a combination of two or more depending on the individual's belief and/or availability of the service nearby. One respondent mentioned:

“... I went to a kabiraj (traditional local healer) in my area, where he gave me medicine and I didn't get a result. I visited him again, he suggested that I go with mustard oil to prepare medicine ..." (IDI 011, 46 year old female)

Half of the respondents experienced some improvement of the symptoms, especially changes in the skin colour or patches which further delayed service seeking. The problem 


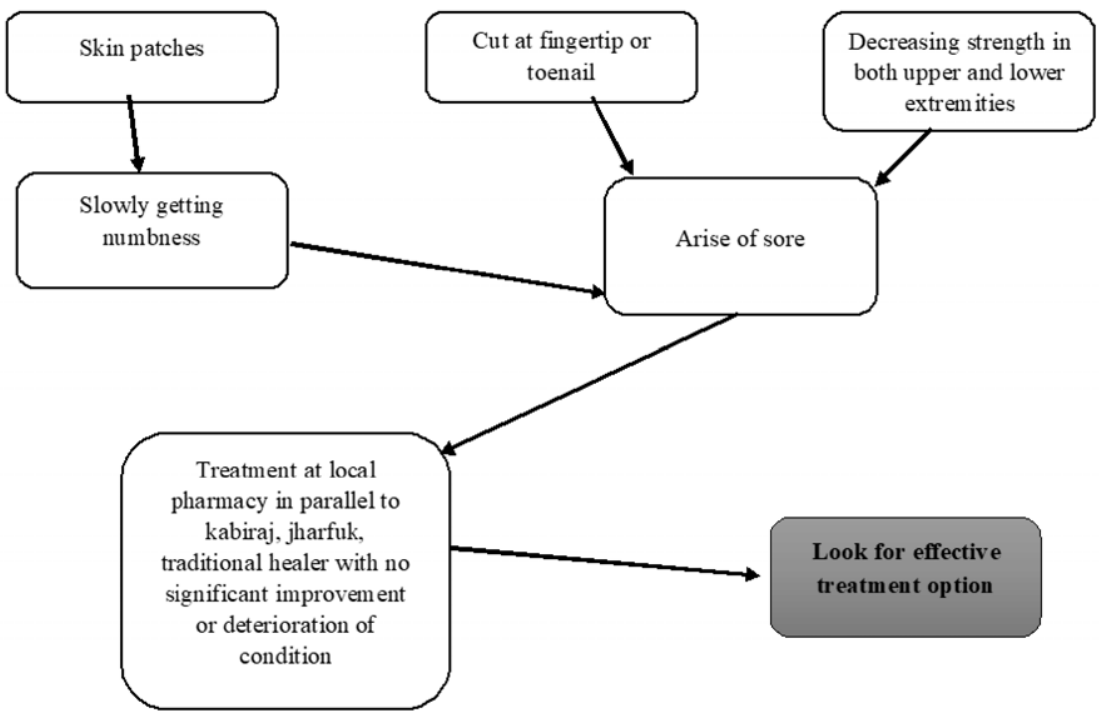

Figure 2. Illness experience of people affected with leprosy.

was aggravated by clawing of hand as well as the inability to extend the toes. This greatly impacted their day to day activities. Dropping objects was a common experience, while some reported burns during cooking. The progression of all symptoms was very slow which was a common experience of all. Figure 2 illustrates the illness progression.

Experiences prior to reaching the leprosy care centre varied amongst individuals. Though MDT is given free of charge, unfortunately, eleven of the 13 subjects did not come straight to the facility because of lack of familiarity. They spent a substantial amount of money at different places for treatment instead. Only two people came to leprosy care centre directly as their family members suffered from leprosy before and had received service at the leprosy care centre.

Two patients were referred to DBLM hospital by consultant doctors suspecting leprosy, but not to the leprosy care centre at the Upazila Health Complex (UHC) where the service is available. It appears that they were unaware of the service at the UHC. Unfortunately, some doctors had treated the persons affected by leprosy for months to see if any improvement occurred which further delayed the referral. Often a relative or a neighbour suggested to visit DBLM hospital for diagnosis of their skin patches. Around half of the participants were admitted to DBLM hospital at least for a few days since they were suffering from unmanageable sores while taking MDT.

Study respondents reported an amount ranging from 20,000 BDT to 200,000 BDT (USD 235-2350 approximately) was spent at other places before reaching UHC, which is a large amount given their socio-economic conditions. Many respondents could not mention the exact amount since they had suffered for a long time. As a primary or only earning member, many of the respondents had to spend a large portion of their family income, and thus needed to curtail their other family needs. One of them uttered:

"... I needed to collect and deposit some money beforehand, so I have money for the expenses. To do that, I had to often minimize the family need on those specific days. There was no income on 
those days, so either I had to loan or collect some for the expenditure of the day ..." (IDI 003, 60 year old male)

MDT service is available at the UHCs across the country. So, all participants were asked to come to their respective Upazila Health Complex for treatment. This study covered four health complexes among six of the districts. The common trend of the clinic is to offer services on specific days of the week in the morning only. The patients reported a travel expense of 100 BDT to 200 BDT (USD 1.5-2.5 approximately) per visit to the health complex. Only a few spent less than 100 BDT. They had to spend 1-3 hours travelling time to and from the clinic. To cover the cost, they had to prearrange the amount or needed to loan every month to collect the medication from health complex. Besides the expenditure, they lost their daily income for those days to attend the clinic. Some people needed an extra caregiver to accompany them to the clinic which was another burden, both in terms of time and cost. One of them mentioned:

“... I need 100 BDT auto-rickshaw fare. So, for coming and going I need around 3 hours and 200 BDT ..." (IDI 008, 37 year old male)

People affected with leprosy expressed their difficulties to pay direct costs and also reported indirect and opportunity costs as barriers to access the MDT at leprosy care centres. The transportation cost of the visit and the loss of income for the day appears as a common burden. Some of them stopped working after the diagnosis which also impacted their family negatively. Often they took a loan to manage the situation but later failed to repay it. Some people could not repair their home which was necessary, whereas others lost their livestock or farming land to cover treatment costs. Often they did not have any money left for the future as all their savings were spent on the treatment. The disease made their family poorer.

\section{Discussion}

The ability to identify and understand the symptoms of a disease is very important in care seeking. It helps an individual to find out and access existing services. The combination of adequate health literacy, health knowledge, beliefs about health and sickness help individuals suffering from a disease to plan their approach to appropriate services. ${ }^{16}$ The symptoms of leprosy develop and progress very slowly and every stage takes a long time to advance to the next, which delay timely and appropriate health-seeking. Participants in this study could not decide what to do with the symptoms, and waited for long until it got worse. Unfortunately, this is a common phenomenon among people affected by leprosy. Muthuvel et al. explained how individuals even did not perceive these symptoms as a problem and waited longer. ${ }^{17} \mathrm{~A}$ study in China revealed a similar pattern of symptoms, namely numbness, tingling sensation of extremities, skin lesions, deformed hand and feet, etc.; participants took self-medication or visited rural doctors, general health services or a dermatologist. The delay in diagnosis was quite long with a mean of 50.18 months. ${ }^{18}$ We did not measure the delay time; however, the participants shared a similar pattern of symptom development and delay in seeking care. The phenomenon is not new but similar to what has been reported elsewhere. A Paraguayan study confirmed that people were not eager to seek treatment as they did not feel any pain in this disease. Traditional beliefs as well as lack of adequate information about leprosy among people cause the delay of diagnosis. ${ }^{19}$ The causes of delay were also reported in a Nepalese study. ${ }^{20}$ To combat the delay, strategies should include extensive education about leprosy in the community with a particular focus on symptoms of the disease. This could be started in the endemic regions. Education programmes should also aim to eliminate incorrect traditional beliefs. 
One large scale survey in India successfully identified hidden cases. ${ }^{21}$ This indicates the important role of organizations in active detection. It is essential to allocate adequate funding for the organizations working in endemic areas to undertake similar surveys in future.

General lack of awareness about the disease seems to be a great barrier to reaching the MDT clinic on time. Meanwhile, frequent visits were reported to the local pharmacy, Kabiraj, traditional healers, faith-based healers, etc. Based on the common symptoms we found in our study, information, education, and communication (IEC) material could be developed to educate the population. It was found that people are interested to know about the causes, signs and symptoms of leprosy through IEC materials as they believe this could help to prevent leprosy. $^{22}$ The IEC materials could be used to guide care seekers at the local service points like pharmacy, traditional healers as people come to these places for service. A general training for pharmacy owners and traditional healers could improve the referral to the leprosy service centre. $^{23}$

Provision of training for skin specialists or dermatologists, especially on diagnosing leprosy symptoms and how to make quick referral to the available services may reduce the delay. Appropriate training to religious leaders, kabiraj and other traditional healers can also help prompt referral of patients to the MDT clinic. ${ }^{24}$

The functional deficit was a prominent issue along with some physical problems including pain, sores and decreasing strength. Rehabilitation professionals may play a vital role at any stage of the disease to stop further deterioration of the conditions. Work simplification techniques should be utilised to minimise functional deficits and damage to the body during work. A physical and occupational therapist should be included in the rehabilitation team under the complete MDT package. ${ }^{25}$

The psychological consequences are also devastating for people affected by leprosy and difficult to cope with. Counselling in the field of leprosy intrevention is a relatively new concept $^{26}$ but a pilot study has already shown a positive outcome. ${ }^{27}$ A psychologist could play a vital role in dealing with depression, anxiety and negative thoughts related to death. This problem should be well addressed during the MDT management to optimise the outcome of treatment and bring patients back into life. Facility field workers face a lot of difficulties to convince suspected persons affected by leprosy to come to the facility, which could be geared under a trained psychologist for a better outcome.

MDT for leprosy is integrated into government health care services and the service is made available at the Upazila Health Complexs. The Upazila Health Complexes are mostly nearby other government offices at the centre of the Upazila. All the services at the facility are free of $\operatorname{cost}^{28}$ however, they need to visit the facility on their own. Besides this service availability, most of the study participants received many kinds of informal services e.g. traditinal healers before receiving MDT. This finding is supported by another recent study which categorised this in a hierarchical pathway starting with self-treatment followed by a traditional healer down to the faith-based and/or western medicine. ${ }^{29}$ Our participants stated that they were not aware of MDT service which was discussed earlier, thus sought available services at the locality where they live. The visit experience to traditional healers prompted the study team to bring them under the referral system, as was suggested by Sima et al. where traditional healers played a vital role in undiagnosed TB case detection. ${ }^{30}$

The Upazila Health Complex may not be very convenient for everyone to seek service. At least two participants mentioned that their homes were on the border between two Upazilas. The closest Upazila Health Complex was located at the other Upazila, but they had to visit their own UHC, which was further away. Inhabitants of one Upazila need to take service at 
their own Upazila health complex. This complexity often discouraged people from starting MDT rather than encouraging them to start treatment near their home. This issue should be considered while starting of MDT, by creating a mechanism for availability of the MDT at the closest health care centre. Extension of the leprosy services to the community clinic level could be a potential way to reach more patients in the community.

Financial obligation is another factor delaying care even after reaching the MDT clinic. Many subjects spent a lot of money before reaching the MDT facility, making them financially weaker. According to the statements of the study participants, managing travel costs back and forth to the facility every month for a year became a burden. If we can arrange the MDT service in the closest UHC, it can make the service more accesible for all. This important economic barrier for disease management needs additional research to help reduce the implementation gap of the programme.

\section{Limitations}

The study exclusively investigated the views of people affected by leprosy but there could be other contributing factors to delay in seeking care. Recall bias might play a role in the interview, since the diseases started a long time ago. Patients identified recently could have given a better perspective. The financial aspects and stigma related to seeking care need to be explored in greater detail to better understand how these delay receiving MDT services.

\section{Conclusion}

Lack of general awareness about the disease and a poor referral system appear to be greatest barriers to care seeking at the early stage of the disease. The cases remain hidden for a long period because of its slow progression and the patients suffer from more devastating disabling conditions. Programmes to improve literacy about leprosy may improve timely access to appropriate care, and enable patients to comply with the treatment requirements and recommendations. Location and functions of leprosy clinics should be made known to the surrounding communities. If informed and made familiar, the community would be more eager to accept the services. Other determinants, such as costs and economic burden, should be further investigated to help formulate policies and strategies to encourage people to seek early and timely care.

\section{Acknowledgements}

We are thankful to C. Ruth Butlin, an independent consultant in the field of leprosy to introduce and link the research team with The Leprosy Mission International Bangladesh. Special thanks goes to the Country Director of The Leprosy Mission International Bangladesh, Mr Salomon Sumon Halder and the whole team for their tireless effort for helping to finalize the data collection process at Nilpahamari.

\section{Funding}

The study was a part of the academic requirement to fulfil the Master of Public Health degree supported by the WHO/TDR Special Postgraduate Programme of Implementation Research on Tropical Diseases. 


\section{Contributors}

Mohammad Monjurul Karim designed the study, prepared the protocol which was submitted to the Ethical Committee, collected data, analysed the data and drafted the paper. Ari Probandari supervised the design of the study and preparation of the protocol and made comments on the draft of the paper. Hasnat Alamgir assisted in conceptualizing the study design and supervised the drafting the paper. Khorshed Alam contributed to drafting the proposal, field data collection. Adi Utarini supervised designing of the study and preparation of the protocol and made comments on the draft of the paper.

All authors were involved in the interpretation of the data and commented on interim drafts. All authors have read and approved the final version of the article. Mohammad Monjurul Karim is the principal and corresponding author.

\section{Declaration of interest}

No conflict of interest to declare.

\section{References}

1 WHO. Leprosy. 2020. Available from: https://www.who.int/news-room/fact-sheets/detail/leprosy.

2 Lastória JC, Abreu MAMM de. Leprosy: review of the epidemiological, clinical, and etiopathogenic aspectsPart 1. An Bras Dermatol, 2014; 89(2): 205-218.

3 WHO. Global leprosy update. 2014: need for early case detection. Wkly Epidemiol Rec, 2015; 90(36): $461-474$.

4 WHO. Neglected Tropical Diseases. World Health Organization, 2020.

5 Moet FJ, Schuring RP, Pahan D, Oskam L, Richardus JH. The prevalence of previously undiagnosed leprosy in the general population of Northwest Bangladesh. PLoS Negl Trop Dis, 2008; 2(2): e198.

6 WHO. Global leprosy update, 2017: reducing the disease burden due toleprosy. Wkly Epidemiol Rec, $2018 ; 93$ : 445-456

7 Brandsma JW, Van Brakel WH. WHO disability grading: operational definitions. Lepr Rev, 2003; 74(4): 366373. [Internet] Available from: https://www.lepra.org.uk/platforms/lepra/files/lr/Dec03/10-366.pdf.

8 Rao PN, Suneetha S. Current situation of leprosy in India and its future implications. Indian Dermatol Online J, 2018; 9(2): 83. [Internet] Available from: http://www.idoj.in/temp/IndianDermatolOnlineJ9283-5522638_152 026.pdf.

9 Keily A. Leprosy in Bangladesh: a situation analysis. Stethoscope, 2016. [Internet] Available from: http://www.theindependentbd.com/magazine/details/31576/Leprosy-in-Bangladesh:-a-situation-analysis.

10 Directorate General of Health Services, Ministry of Health and Family Welfare. Operational Plan Tuberculosis and Leprosy (TB \& Lep.) Control. 2011. [Internet] Available from: https://www.medbox.org/operational-plan -tuberculosis-and-leprosy-tb-lep-control/download.pdf.

11 Ek Nojore Nilphamari Zila. Bangaldesh Jatiyo Tattha Batayon. 2020 [Internet] [cited 2020 January 9] Available from: http://www.nilphamari.gov.bd/site/page/30dcdbf3-18fd-11e7-9461-286ed488c766/.

12 Alamgir M. 100pc literacy still a far cry. The Daily Star, 2019. [Internet] [cited 2020 January 9] Available from: https://www.thedailystar.net/frontpage/literacy-rate-in-bangladesh-2019-100-pc-still-far-cry-1796734.

13 The World Bank. Bangladesh Interactive Poverty Maps. The World Bank. 2020. [Internet] [cited 2020 January 9] Available from: https://www.worldbank.org/en/data/interactive/2016/11/10/bangladesh-poverty-maps?fbcli d=IwAR2OGaG9KAB8VQvc6LHpwNR16iSSUjRH2QdPZlk4y8BAYS03y5qMC7w9UnQ.

14 Programme DG of HSNLE. NLEP Annual Disease Profile Report 2017. 2017.

15 National Leprosy Elimination Programme: Bangladesh: District Annual Report 2017. 2017.

16 Levesque J-F, Harris MF, Russell G. Patient-centred access to health care: conceptualising access at the interface of health systems and populations. Int J Equity Health, 2013; 12(1): 18. [Internet] Available from: https://equit yhealthj.biomedcentral.com/track/pdf/10.1186/1475-9276-12-18.

17 Muthuvel T, Govindarajulu S, Isaakidis P, Shewade HD, Rokade V, Singh R et al. "I wasted 3 years, thinking it's not a problem": patient and health system delays in diagnosis of leprosy in India: a mixed-methods study. PLoS Negl Trop Dis, 2017; 11(1): e0005192. [Internet] Available from: https://journals.plos.org/plosntds/articl e/file?id=10.1371/journal.pntd.0005192\&type=printable.

18 Zhang F, Chen S, Sun Y, Chu T. Healthcare seeking behaviour and delay in diagnosis of leprosy in a low endemic area of China. Lepr Rev, 2009; 80(4): 416-423. [Internet] Available from: http://www.ncbi.nlm.nih.gov/pubm ed/20306640. 
19 Nicholls PG, Wiens C, Smith WCS. Delay in presentation in the context of local knowledge and attitude towards leprosy - the results of qualitative fieldwork in Paraguay. Int J Lepr Other Mycobact Dis, 2003; 71(3): 198. [Internet] Available from: http://lepr.allenpress.com/lepronline/?request=get-abstract\&doi=10.1489/1544-581 X(2003)71\%3C198:DIPITC\%3E2.0.CO;2.

20 Subedi M, Engelbrektsson U-B. Factors contributing to delay in diagnosis and start of treatment of leprosy: analysis of help-seeking narratives from a community study in Dang District. Dhaulagiri J Sociol Anthropol, 2018; 12: 11-17. [Internet] Available from: https://www.nepjol.info/index.php/DSAJ/article/view/22175.

21 Katoch K, Aggarwal A, Yadav VS, Pandey A. National sample survey to assess the new case disease burden of leprosy in India. Indian J Med Res, 2017; 146(5): 585-605. [Internet] Available from: http://www.ncbi.nlm.ni h.gov/pubmed/29512601.

22 Abner O, Ferdinand D, Junelyn T, Ruby L. Developing Evidence-based Leprosy Information, Education, and Communication (IEC) Materials for the Cordillera Administrative Region (CAR). 2012; 2012 (Sep.).

23 Atre SR, Rangan SG, Shetty VP, Gaikwad N, Mistry NF. Perceptions, health seeking behaviour and access to diagnosis and treatment initiation among previously undetected leprosy cases in rural Maharashtra, India. Lepr Rev, 2011; 82(3): 222-234. [Internet] [cited 2020 January 10] Available from: http://www.ncbi.nlm.nih.gov/p ubmed/22125930.

24 Alamsyah T, Usman S, Yusuf M, Elvin SD. Effectiveness of traditional healers in program to control leprosy in Nagan Raya District in Aceh. Dermatol Res Pract, 2018; 2018: 1-6. [Internet] Available from: https://www.hindawi.com/journals/drp/2018/3176762/.

25 MacRae C, Kopalakrishnan S, Faust L, Klowak M, Showler A, Klowak SA et al. Evaluation of safety tool for ambulatory leprosy patients at risk of adverse outcome. Trop Dis Travel Med Vaccines, 2018; 4(1): 1. [Internet] [cited 2019 December 5] Available from: https:/www.ncbi.nlm.nih.gov/pmc/articles/PMC5833028/pdf/40794 _2018_Article_61.pdf.

26 Lusli M, Zweekhorst MBM, Miranda-Galarza B, Peters RMH, Cummings S, Seda FSSE et al. Dealing with stigma: experiences of persons affected by disabilities and leprosy. Biomed Res Int, 2015; 2015: 1-9. [Internet] [cited 2021 May 16] Available from: 10.1155/2015/261329.

27 Floyd-Richard M, Gurung S. Stigma reduction through group counselling of persons affected by leprosy-A pilot study. Lepr Rev, 2000; 71:499-504

28 Islam MS. Fight leprosy, fight stigma. The Daily Star, 2016. [Internet] [cited 2019 March 6] Available from: ht tps://www.thedailystar.net/star-weekend/apple-day/fight-leprosy-fight-stigma-1301659.

29 Ebenso B, Newell J, Emmel N, Adeyemi G, Ola B. Changing stigmatisation of leprosy: an exploratory, qualitative life course study in Western Nigeria. BMJ Glob Heal, 2019; 4(2): e001250. [Internet] [cited 2020 January 10] Available from: https://gh.bmj.com/content/bmjgh/4/2/e001250.full.pdf.

30 Sima BT, Belachew T, Bjune G, Abebe F. Traditional healers' role in the detection of active tuberculosis cases in a pastoralist community in Ethiopia: a pilot interventional study. BMC Public Health, 2019; 19(1): 721. [Internet] [cited 2019 December 6] Available from: https://bmcpublichealth.biomedcentral.com/track/pdf/10.1 186/s12889-019-7074-9. 